\title{
Design and Experimental Study of Progressive Spring for Formula Student Race Car
}

\section{Anmol Shripad Patil}

Savitribai Phule Pune University https://orcid.org/0000-0003-4144-8963

\section{Eshita Nandi}

Savitribai Phule Pune University

Prasad Nanasaheb Punekar ( $\nabla$ prasadpunekar29@gmail.com )

Abhang Colony, Rahatani, Kalewadi

\section{Suyash Wagh}

Savitribai Phule Pune University

\section{Original Article}

Keywords: suspension, progressive springs, spring rate, ride quality, compression

Posted Date: September 27th, 2021

DOl: https://doi.org/10.21203/rs.3.rs-856008/v1

License: (9) This work is licensed under a Creative Commons Attribution 4.0 International License. Read Full License 


\title{
Design and Experimental Study of Progressive Spring for Formula Student Race Car
}

\author{
Anmol Shripad Patil ${ }^{1}$, Eshita Nandi ${ }^{2}$, Prasad Nanasaheb Punekar ${ }^{3^{*}}$,Suyash Wagh ${ }^{4}$ \\ * Correspondence (Prasad Nanasaheb Punekar): prasadpunekar29@gmail.com \\ ${ }^{1}$ Flat no. D-303, Olympia Society, Wakad, Pune-411056 \\ ${ }^{2}$ Flat no.403 ,A2 building,Manik Baug Orchid,opp anna magar saheb stadium,pimpri pune -18 \\ ${ }^{3}$ Abhang Colony, Rahatani, Kalewadi, Pune-411017. \\ ${ }^{4}$ Building No.16, Room No. 06, Police Headquarters, Gangapur Road, Nashik-4220
}

\begin{abstract}
:
The purpose of carrying out the present work is to design, manufacture \& test the progressive springs on an FS vehicle. This is one type of helical spring with a variable spring rate. The main purpose of designing progressive springs is to avail all the advantages of the variable spring rate over the linear spring rate and better ride quality along with roll control, compared to linear rate springs. We took several factors of vehicle dynamics under consideration before settling on progressive springs. Before starting with the design procedure, we had set objectives and followed the standard methodology of spring design to get the required output.

Along with that, we took design philosophy under consideration. We reviewed all the parameters before finalizing the spring material as it is one of the major factors. We carried out all the necessary design calculations to complete the dimensions and stiffness of the spring. The conclusion helped us to achieve better ride quality and roll control accompanying the optimized spring design satisfying all the necessities such as load, stiffness, and deflection of progressive springs.
\end{abstract}

Keywords: suspension; progressive springs; spring rate; ride quality; compression

\section{INTRODUCTION:}

FS car's suspension springs compress to absorb impact when tires roll over irregular terrain and keep the car off the ground in correspondence with the damper. The two types of springs used in race cars are linear and progressive. Which one do you think is best for FS cars? On the one hand, progressive-rate springs generally have less total deflection; they also provide the benefits of a lowered car - better handling, reduced nose dive, and decreased body roll, along with better ride quality. This is because the closely wound coils needed to create the dual rates take up deflection space. As a progressive spring compresses, the spring rate will gradually increase. On the other hand, in linear springs, the spring rate is constant, and it is not affected by the load acting on the spring. In this paper, a detailed design procedure and analytical calculation of progressive spring for FS car followed by the experimental study whose results were obtained by spring load testing machine are explained.

\section{METHODOLOGY:}

\subsection{Problem Statement}

Why choose progressive rate springs over linear rate springs? Progressive springs contribute to the roll control of the vehicle. A progressive spring does not have a constant rate of deflection. For this reason, they are called variable rate springs. Since racetracks have different road surfaces, a suspension that is adaptive to changing with road surfaces is desired. It also means to achieve a compliant suspension in the rough and a tight suspension for high-speed turns. Whereas linear springs allow working easily because the spring rate is constant, this results in quick tuning as many teams avoid risking in terms of suspension settings. Hence progressive springs become a great advantage.

But even after choosing progressive, how will one assure whether it is satisfactory or not? Rather how will one determine the behavior of spring? So that is when the experimental study comes into play which has to go hand in hand with the theoretical research. The load testing setup provides us with estimated results that are further validated with results from testing a car and running it on progressive springs. And then, it leads to the final lock to the tuning.

\subsection{Objectives}

1. To achieve better ride quality and superior handling due to the roll control offered by the springs.

2. To get a lower ride height, increased stiffness through hard cornering, and a more comfortable ride over a 
stiffer ride.

3. To avail the advantages of the dual stiffness over the different track conditions.

4. To validate the design by correlating design calculations with the testing results data.

\subsection{Abbreviations}

1. FS- formula student

2. $\mathrm{k}$ - spring stiffness

3. $\mathrm{k}_{1}$ - spring stiffness of softer region of coil

4. $\mathrm{k}_{2}$ - spring stiffness of stiffer region of coil

5. $W$ - load acting on spring

6. $W_{l}$ - load acting on softer region of coil

7. $W_{2}$ - load acting on stiffer region of coil

8. $\delta$ - deflection of spring

9. $\delta_{\text {max }}$ - maximum deflection of spring
10. $\delta_{1}$ - deflection of softer region of spring

11. $\delta_{2}-$ deflection of stiffer region of spring

12. d - spring diameter

13. $L_{S^{-}}$solid length of spring

14. $L_{f}$ - free length of total number of coils

15. $L_{f 1}$ - free length of softer region of spring

16. $L_{f 2}$ - free length of stiffer region of spring

17. D - mean diameter of coil

18. G / g - Modulus of Rigidity

19. $\mathrm{n}^{1}-$ total number of coils

20. $\mathrm{n}$ - total active number of coils

21. $\mathrm{n}_{1}$-total active number of coils of softer region of spring

22. $\mathrm{n}_{2}$-total active number of coils od stiffer region of spring

\subsection{Design Procedure}

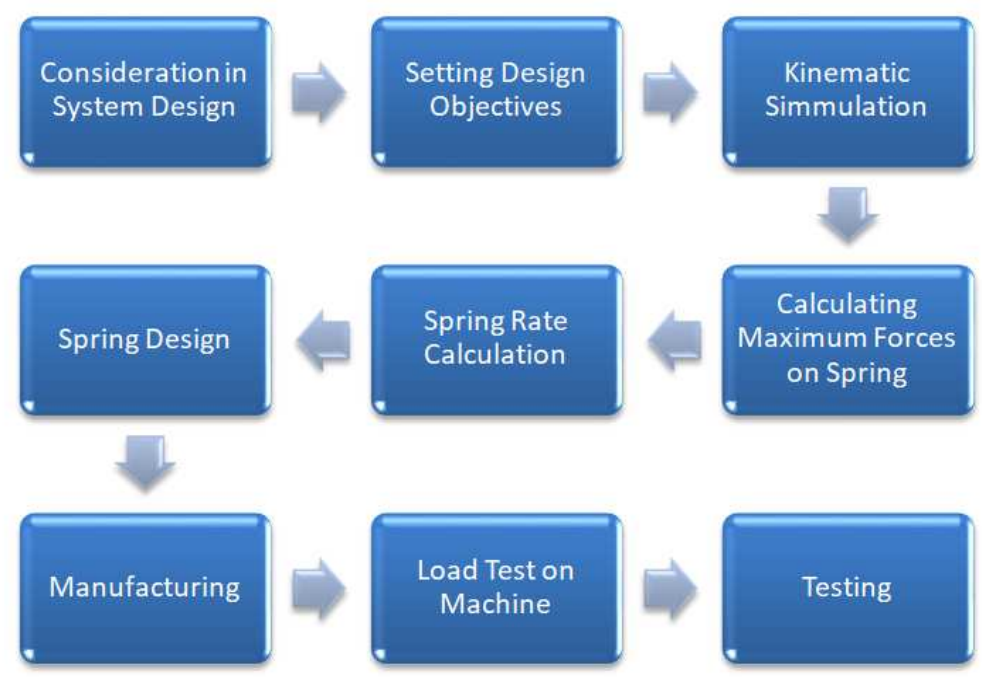

Fig. 1 Flow chart of a design procedure for springs

\subsection{Design Philosophy}

1. Calculation of force to be applied on spring.

2. Figuring out solid height will also be based on the calculated force. The spring should not compress to its solid height before all the force is applied.

3. Based on this calculated force, wire is selected. 4. Spring design takes careful consideration, precise calculations, and the right expertise.

5. Spring model.

\subsection{Spring Material}

The selection of spring materials depends on the following factors:

1. Maximum load acting on the spring.

2. Set of stress through which the spring operates.

3. Constraints of mass and volume of spring.

4. Expected fatigue life.

5. Environmental conditions such as temperature and corrosive atmosphere.

6. Severity of deformation encountered while making spring. 


\begin{tabular}{|c|c|c|}
\hline Sr. No. & Parameter & Specification \\
\hline 1 & Raw Material & Sp.St.GR-III \\
\hline 2 & Wire Diameter & $6.00 \mathrm{~mm}$ \\
\hline 3 & Outside Diameter & $47.00 \mathrm{~mm}$ \\
\hline 4 & Mean Diameter & $41.00 \mathrm{~mm}$ \\
\hline 5 & Total Coil & $12.00 \mathrm{Nos}$ \\
\hline 6 & Active Coil & 10.00 Nos \\
\hline 7 & Free Length & $140.00 \mathrm{~mm}$ \\
\hline 8 & Coil Upper Length (Low Pitch) & $65.00 \mathrm{~mm}$ \\
\hline 9 & Coil Lower Length (High Pitch) & $75.00 \mathrm{~mm}$ \\
\hline 10 & Solid Length & $72.00 \mathrm{~mm}$ \\
\hline
\end{tabular}

Table 1: Design parameters and respective specifications of progressive spring.

\subsection{Design Calculation}

NOTE: a) Initially $\mathrm{K}$ is assumed on the basis of maximum load acting, deflection required and free length

constraint.

b) If we need to increase the load capacity, we need to increase the stiffness and decrease the deflection

$$
\uparrow k=\frac{W}{\delta \downarrow}
$$

c) To decrease the $L_{f}$, we need to decrease the number of coils, i.e., increase the pitch Keeping the stiffness constant.

a)

$$
\begin{aligned}
& \mathrm{d}=6 \mathrm{~mm} \\
& \mathrm{D}=41.6 \mathrm{~mm} \\
& \mathrm{k}_{1}=29 \mathrm{~N} / \mathrm{mm} \text { (assumed stiffness) } \\
& \mathrm{G}=79.344 \times 10^{3} \mathrm{~N} / \mathrm{mm}^{\wedge} 2 \\
& \mathrm{n}_{1}=? \\
& L_{f 1}=? \\
& \mathrm{k}=\frac{\boldsymbol{g d}^{4}}{\mathbf{8 D}^{3} \boldsymbol{n}}
\end{aligned}
$$

Therefore $\mathrm{n}_{1}=\frac{g d^{4}}{8 D^{3} k 1}=\frac{79.344 \times 10^{3} \times 6^{4}}{8 \times 41.6^{3} \times 29}$

$n_{1}=6.1567$

$L_{f 1}=L_{S}+\delta_{\max }+\left(n^{1}-1\right) \times 1$

$L_{f 1}=\left(n^{1} d\right)+\delta_{\max }+\left(n^{1}-1\right) \times 1$

$n^{1}=$ total number of coils.

On each side of coil, the no. of inactive coil will be 1.

Therefore,

$L_{f}=(n+1) d+\delta_{\max }+\left(n^{1}+1-1\right) \times 1$

$L_{f}=(n+1) d+\delta_{\max }+n \times 1$

$L_{f 1}=\left(\mathrm{n}_{1}+1\right) \mathrm{d}+\delta_{1}+\mathrm{n}_{1} \times 1$

$L_{f 1}=(6.1567+1) 6+\delta_{1}+6.1567$

Constraint of deflection.

Therefore,

Max deflection $=\delta_{\max }=55.8 \mathrm{~mm}$-------- Total

But, we need, total deflection $\times \frac{1}{3}$-------(for low pitch coils) 
$\delta_{1}=55.8 \times \frac{1}{3}$

$\delta_{1}=18.6$

Now,

$\delta_{1}=\frac{8 W D^{3} n}{G d^{4}}$

$\delta_{1}=18.6 \mathrm{~mm}$

$\mathrm{D}=41.6 \mathrm{~mm}$

$\mathrm{d}=6 \mathrm{~mm}$

$\mathrm{n}=6.1567 \mathrm{~mm}$

$\mathrm{G}=79.344 \mathrm{~N} / \mathrm{mm}^{\wedge} 2$

Therefore

$W_{l}=539.4038 \mathrm{~N}$

From (5) and (6)

$L_{f 1}=(6.1567+1) 6+18.6+6.1567$

$L_{f 1}=67.6969 \mathrm{~mm}$

$k=\frac{W}{\delta}$ equation satisfied

b) $\mathrm{d}=6 \mathrm{~mm}$

$$
\begin{aligned}
& \mathrm{D}=41.6 \mathrm{~mm} \\
& \mathrm{k}_{2}=37 \mathrm{~N} / \mathrm{mm} \text { (assumed stiffness) } \\
& \mathrm{G}=79.344 \times 10^{3} \mathrm{~N} / \mathrm{mm} \\
& n_{2}=? \\
& L_{f 2}=? \\
& \mathrm{k}_{2}=\frac{g d^{4}}{8 D^{3} n}
\end{aligned}
$$

Therefore

$\mathrm{n}_{2}=\frac{g d^{4}}{8 D^{3} k 2}=\frac{79.344 \times 10^{3} \times 6^{4}}{8 \times 41.6^{3} \times 37}$

$$
n_{2}=4.8256
$$

Remaining deflection $=(55.8-18.6)$

$$
\delta_{2}=37.2 \mathrm{~mm}
$$

The maximum load is given by

$$
\begin{aligned}
& \delta_{2}=\frac{8 W D^{3} n 2}{G d^{4}} \\
& W=\frac{\delta_{2} \times G d^{4}}{8 D^{3} n 2} \\
& W_{2}=1376.3875 \mathrm{~N} \\
& L_{f 2}=\left(n^{1} d\right)+\delta_{2}+\left(n^{1}-1\right) \times 1 \\
& L_{f 2}=\left(\mathrm{n}_{2}+1\right) \mathrm{d}+\delta_{2}+\left(\mathrm{n}_{2}+1-1\right)^{* 1} \\
& L_{f 2}=(\mathrm{n} 2+1) \mathrm{d}+\delta_{2}+\mathrm{n}_{2}
\end{aligned}
$$

$W=$ Total load that the coils can take

$W=W_{1}+W_{2}=1915.7913 \mathrm{~N}$

Total coils $=4.8256+6.1567+$ Inactive coils

$$
\begin{aligned}
& =10.9823+2 \\
& =12.9823
\end{aligned}
$$

$L_{f}=L_{f 1}+L_{f 2}=144.6758 \mathrm{~mm}$

\section{RESULTS:}

The designed spring is being tested on an industrial spring testing machine. The results of testing are given in the form of load v/s deflection graph shown in fig. 2 .

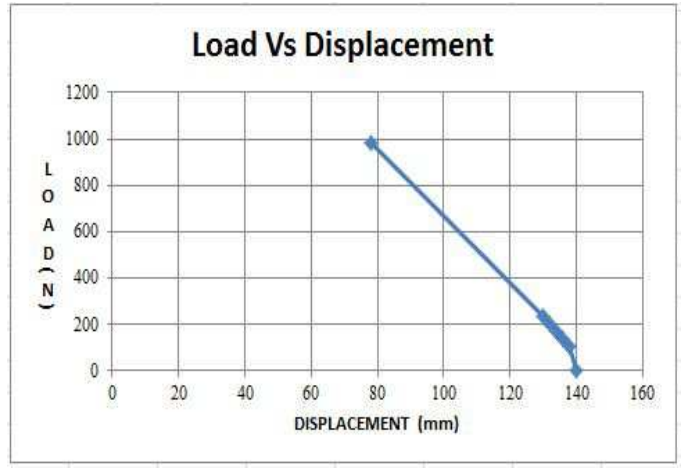

Fig.2 Load v/s Displacement graph

\section{DISCUSSION:}

The spring's progressive behavior could be observed from fig.2 Load v/s deflection graph. Initially, the graph is non-linear and then it turns into linear which indicates that at the beginning the load required to deflect the spring up to certain extent is less, and afterward as the deflection goes on increasing the load required increases linearly.

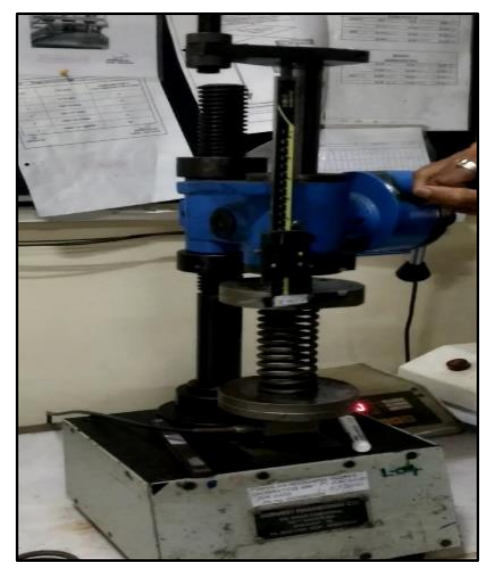

Fig. 3 Progressive springs on testing setup

$L_{f 2}=76.9789 \mathrm{~mm}$ 


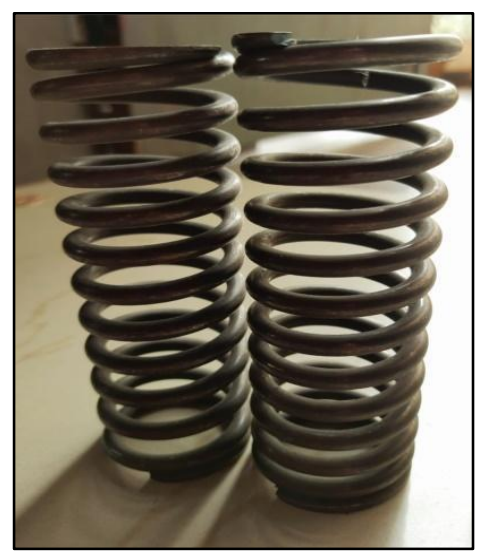

Fig. 4 Manufactured and tested model

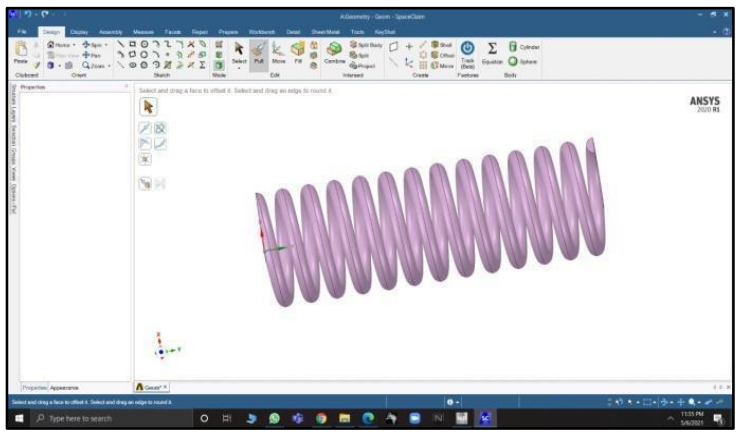

Fig. 5 Design Model of Progressive Springs

\section{CONCLUSIONS:}

In this research paper, part of the discussion is a study about the design of progressive springs for FS cars. This attempt was helpful to get successful results, as we tested the progressive springs on the FS car and an industrial spring testing machine. The stiffness of $29 \mathrm{~N} / \mathrm{mm}$ at the softer region and 37 $\mathrm{N} / \mathrm{mm}$ at the stiffer region was being finalized, and the spring with this stiffness fulfilled the aim of both the softer rate at the low load and the stiffer rate for the sharp turns. The stiffness of springs increased with increasing load in parabolic nature. This fascinated the required load transfer at corners. Its starting low stiffness also provided comfort to the driver at small bumps and droops. It provides the required stiffness as well as the maximum strength, which was necessary for our design. At the same time, it also satisfied all the constraints of free length, maximum bump travel, and droop travel. The iteration we performed to achieve the required stiffness within the constraints was successful, and the design gave us the needed results on testing. We validated the spring design with the help of actual testing.

\section{DECLARATIONS:}

\section{Acknowledgement:}

We thankfully acknowledge Suaan Techmechs Pvt Ltd of India and Team Redline Racing of JSPM's Rajarshi Shahu College of Engineering of India for their support.

\section{Authors' Contributions:}

Anmol Shripad Patil was in charge of the complete research and design process. Prasad Nanasaheb Punekar and Suyash Wagh together monitored complete experimentation and manufacturing process. Eshita Nandi managed and analyzed the testing.

\section{Authors' Information:}

Anmol Shripad Patil, born in 2001, is currently pursuing B.E. in mechanical engineering with Savitribai Phule Pune University, Pune. $\mathrm{He}$ is interested in field of research on robotics and automation.

Eshita Nandi, born in 1999, has completed B.E. in mechanical engineering from Savitribai Phule Pune University, Pune. Her main interest lies in research of automobiles.

Prasad Nanasaheb Punekar, born in 2000, is currently pursuing B.E. in mechanical engineering with Savitribai Phule Pune University, Pune. He is interested in field of research on mechanical design and automation.

Suaysh Wagh, born in 1998, is pursuing M.Sc. mobility engineering with Charmers University of Technology, Sweden. His is mainly interested in automotives research.

Availability of Data and Materials:

Not Applicable.

\section{Funding:}

Not Applicable.

\section{Competing Interests:}

No competing financial and non-financial interests.

\section{REFERENCES:}

1. https://www.hypercoils.com , linear...Web results Linear vs. Progressive Rate Suspension Springs | Tech Tips | Hyperco

2. Design Of Machine, McGraw hill, VB Bhandari

3. https://www.progressivesuspension.com

4. Web results

5. Progressive Suspension: High-performance motorcycle suspension ...

6. https://en.m.wikipedia.org > wiki

7. Spring (device) - Wikipedia

8. RCVD (Race Car Vehicle Dynamics) 